\title{
EFFECT OF NICKEL DOPANT ON STRUCTURAL, MORPHOLOGICAL AND OPTICAL CHARACTERISTICS OF $\mathrm{Fe}_{3} \mathrm{O}_{4}$ NANOPARTICLES
}

\author{
T. Kamakshi ${ }^{1,3^{*}}$, G. Sunita Sundari ${ }^{1}$, Harikrishna Erothu ${ }^{2}$ \\ and R. Subhakaran Singh ${ }^{2}$ \\ ${ }^{1}$ Department of Physics, Koneru Lakshmaiah Education Foundation (KLEF), Vaddeswaram, \\ Guntur-522502, Andhra Pradesh, India. \\ ${ }^{2}$ Centre for Advanced Energy Studies (CAES), KoneruLakshmaiah Education Foundation \\ (KLEF), Vaddeswaram, Guntur-522502, Andhra Pradesh, India. \\ ${ }^{3}$ Department of Physics, MallaReddy Engineering College for Women,Maisammaguda, \\ Dhulapally, Secunderabad-500100, Telangana, India. \\ *E-mail: kamakshi.gopavarapu@gmail.com
}

\begin{abstract}
In this current work, the effect of different concentrations of nickel (Ni) dopant on the structural, morphological and optical properties of undoped $\mathrm{Fe}_{3} \mathrm{O}_{4}$ nanoparticles (NPs) are analyzed. Nickel doped $\mathrm{Fe}_{3} \mathrm{O}_{4}\left(\mathrm{NiFe}_{3} \mathrm{O}_{4}\right) \mathrm{NPs}$ of five concentrations can be represented as $0.5 \%$ as NF1, $1.0 \%$ as NF2, $1.5 \%$ as NF3, $2 \%$ as NF4 and $2.5 \%$ as NF5. Undoped $\mathrm{Fe}_{3} \mathrm{O}_{4}$ and $\mathrm{NiFe}_{3} \mathrm{O}_{4} \mathrm{NPs}$ are prepared by Chemical co-precipitation method from a mixture of $\mathrm{FeCl}_{2} \cdot 4 \mathrm{H}_{2} \mathrm{O}$ and $\mathrm{FeCl}_{3} \cdot 6 \mathrm{H}_{2} \mathrm{O}$ salts. Structural, morphological and optical properties of the synthesized undoped $\mathrm{Fe}_{3} \mathrm{O}_{4}$ and $\mathrm{NiFe}_{3} \mathrm{O}_{4}$ NPs were deliberated by a choice of characterization techniques such as XRD, FTIR, FE-SEM and UVVIS. XRD established the characteristic structure, phase and purity of the synthesized undoped $\mathrm{Fe}_{3} \mathrm{O}_{4}$ and $\mathrm{NiFe}_{3} \mathrm{O}_{4}$ NPs; Average crystallite size is found to decrease with increasing Ni concentration. Surface morphology of undoped $\mathrm{Fe}_{3} \mathrm{O}_{4}$ and $\mathrm{NiFe}_{3} \mathrm{O}_{4} \mathrm{NPs}$ was studied by scanning electron microscopy (SEM). The existence of FTIR peaks at $563.2 \mathrm{~cm}^{-1}$ and $433.5 \mathrm{~cm}^{-1}$ confirmed the formation of $\mathrm{Fe}_{3} \mathrm{O}_{4} \mathrm{NPs}$. It is due to the stretching vibrations of the Fe-O bond. The optical absorption of the synthesized nanomaterials was studied by DR UV-Vis spectrometer. Band gap measurements revealed that the indirect band gap values for synthesized Ni-doped nanomaterials $(1.25 \mathrm{eV})$ are higher than the determinant value for the undoped $\mathrm{Fe}_{3} \mathrm{O}_{4} \mathrm{NPs}(0.75 \mathrm{eV})$ due to a decrease in lattice constant. The results indicated that the Ni-doped $\mathrm{Fe}_{3} \mathrm{O}_{4}$ NPs strongly influences the microstructure, crystal structure and energy band gap.
\end{abstract}

Keywords: Nickel doped $\mathrm{Fe}_{3} \mathrm{O}_{4}$ nanomaterials, FTIR, FE-SEM, DR-UV-Visible, XRD analysis.

(C) RASĀYAN. All rights reserved

\section{INTRODUCTION}

Iron oxide is available in three phases in nature are $\mathrm{Fe}_{3} \mathrm{O}_{4}, \gamma-\mathrm{Fe}_{2} \mathrm{O}_{3}$ and $\alpha-\mathrm{Fe}_{2} \mathrm{O}_{3}$ and, it is one of the most important transitions metal oxide ${ }^{1}$. The catalytic activity, biocompatibility, low-cost, non-toxicity and environmentally friendly nature of iron oxide materials leads to great research interest ${ }^{2}$. Metal oxide nanoparticles have widespread applications in energy materials, thermochromic, magnetism, biomedicine, imaging, communications technology and data storage, catalysts for organic transformations and super hydrophobic surfaces ${ }^{3}$. Among all, $\mathrm{Fe}_{3} \mathrm{O}_{4}$ (magnetite) is a most extensively studied ferrimagnetic oxide that has an inverse spinel structure. It attributes distinctive magnetic and electric properties due to the electron hopping between $\mathrm{Fe}^{2+}$ and $\mathrm{Fe}^{3+}$ ions in the octahedral sites. It is famous that the catalytic activity of $\mathrm{Fe}_{3} \mathrm{O}_{4}$ could be improved by doping them with transition metal ions ${ }^{4}$.

A broad selection of methods include co-precipitation, wet chemical reduction synthesis ${ }^{6}$, electrochemical ${ }^{7}$, solid state reaction ${ }^{8}$, microwave-assisted $^{9}$, sol-gel method ${ }^{10}$, Novel flow injection ${ }^{11}$,

Rasayan J. Chem., 12(2), 531-536(2019)

http://dx.doi.org/10.31788/RJC.2019.1225054

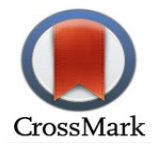


Hydrothermal Preparation ${ }^{12}$, solvothermal ${ }^{13}$, have been reported for the preparation of $\mathrm{Fe}_{3} \mathrm{O}_{4}$ nanoparticles ${ }^{14}$. In this article, we reported the synthesis of Ni-doped $\mathrm{Fe}_{3} \mathrm{O}_{4} \mathrm{NPs}$ using simple chemical co-precipitation technique.

The aim of this work was to study the effect of nickel dopant on structural, morphological and optical characteristics of the prepared $\mathrm{Fe}_{3} \mathrm{O}_{4}$ nanoparticles by different characterization techniques, for instance, XRD, FTIR, FE-SEM and UV-VIS. The obtained results are deeply discussed in this research paper.

\section{Material}

\section{EXPERIMENTAL}

Chemical reagents such as Ferrous chloride tetrahydrate $\left[\mathrm{FeCl}_{2} \cdot 4 \mathrm{H}_{2} \mathrm{O}\right.$ (99\%)] and Nickel(II) nitrate hexahydrate $\left[\mathrm{Ni}\left(\mathrm{NO}_{3}\right)_{2} \cdot 6 \mathrm{H}_{2} \mathrm{O}(99 \%)\right]$ obtained from Sigma Aldrich, Ferric chloride hexahydrate [FeCl $\left.3.6 \mathrm{H}_{2} \mathrm{O}(99 \%)-\mathrm{LR}\right]$ from Dr. MACS BIO-PHARMA PRIVATE LIMITED, Sodium sulfate from Quality traders, were used as received.

Synthesis of undoped $\mathrm{Fe}_{3} \mathrm{O}_{4}$ and different concentrations of Ni-doped $\mathrm{Fe}_{3} \mathrm{O}_{4} \quad\left(\mathrm{NiFe}_{3} \mathrm{O}_{4}\right)$ Nanoparticles [0.5 atomic \% of Ni-doped $\mathrm{Fe}_{3} \mathrm{O}_{4}(\mathrm{NF} 1), 1$ atomic \% of Ni-doped $\mathrm{Fe}_{3} \mathrm{O}_{4}(\mathrm{NF} 2), 1.5$ atomic \% of Ni-doped $\mathrm{Fe}_{3} \mathrm{O}_{4}$ (NF3), 2 atomic\% of Ni-doped $\mathrm{Fe}_{3} \mathrm{O}_{4}$ (NF4) and 2.5 atomic \% of Nidoped $\mathrm{Fe}_{3} \mathrm{O}_{4}$ (NF5)].

Aqueous solution $(25 \mathrm{~mL})$ consist of $2 \mathrm{~g}$ of $\mathrm{FeCl}_{3} \cdot 6 \mathrm{H}_{2} \mathrm{O}$ and $5.4 \mathrm{~g}$ of $\mathrm{FeCl}_{2} \cdot 4 \mathrm{H}_{2} \mathrm{O}$ and its $\mathrm{Fe}^{2+} / \mathrm{Fe}^{3+}$ ratio is found to be 1:2. The solution mixture was vigorously stirred at room temperature for $30 \mathrm{~min}$. Now, $\mathrm{NH}_{4} \mathrm{OH}$ solution $\left(\mathrm{NH}_{3}\right.$ about $25 \%$ ) was added quickly to the above mixture under continuous stirring. Initially, the brown precipitate is obtained and turns to black after $30 \mathrm{~min}$. stirring. The precipitate is then washed with distilled water till it reaches to $\mathrm{pH}=7$. Then obtained precipitate was dried at $60^{\circ} \mathrm{C}$ in a hot air oven. Similar steps are followed for the synthesis of $\mathrm{Ni}$-doped $\mathrm{Fe}_{3} \mathrm{O}_{4}$ for all five concentrations $(0.5,1.0$, $1.5,2$ and 2.5 atomic percentages) using $\mathrm{Ni}\left(\mathrm{NO}_{3}\right)_{2} \cdot 6 \mathrm{H}_{2} \mathrm{O}$ as precursor ${ }^{15}$.

\section{Characterizations}

Bruker Kappa APEXII FEI Quanta FEG 200 High-Resolution Scanning Electron Microscope (FE-SEM) was used for studying the morphology of the product.Crystal structure of the Nanomaterialswas studied from Bruker AXS D8 Advance X-ray Powder Diffractometer with $\alpha-\mathrm{Cu}, \lambda$ is $1.5406{ }^{\circ} \mathrm{A}$. The FTIR studies were performed on a Thermo Nicolet, Avatar 370 instrument. The UV-Vis absorption spectra of the nanoparticles (NPs) were obtained by a UV-VIS-NIR Spectrophotometer (Varian, Cary 5000).

\section{Structural Properties}

\section{RESULTS AND DISCUSSION}

\section{XRD}

Figure-1 represents the XRD pattern of undoped $\mathrm{Fe}_{3} \mathrm{O}_{4} \mathrm{NPs}$ and $\mathrm{Fe}_{3} \mathrm{O}_{4} \mathrm{NPs}$ doped with different amounts of $\mathrm{Ni}^{2+}(0.5 \%, 1 \%, 1.5 \%, 2 \%$ and $2.5 \%)$. The observed diffraction peaks of all samples exactly match to standard pattern characteristic peaks of the $\mathrm{Fe}_{3} \mathrm{O}_{4}$ cubic structure (JCPDS No.85-1436). Secondary phase like $\mathrm{Ni}-\mathrm{O}, \mathrm{Ni}$ and $\mathrm{Fe}-\mathrm{O}$ were not found in the XRD pattern suggesting the synthesis of high-quality $\mathrm{NiFe}_{3} \mathrm{O}_{4}$ nanomaterials (NPs) through chemical co-precipitation method. The XRD data showed that the addition of $\mathrm{Ni}^{2+}$ dopant in $\mathrm{Fe}_{3} \mathrm{O}_{4}$ lattice doesn't alter its lattice due to $\mathrm{Ni}^{2+}$ acts similar to $\mathrm{Fe}^{2+}$ ions at the deposition and formation steps ${ }^{16,17}$. But it produces a slight shift in diffraction peaks towards higher $2 \theta$ values and also the intensity of the peak (311) improved for NF1 due to dopant added due to the ionic radius of $\mathrm{Ni}^{2+}(69 \mathrm{pm})$ is lower than $\mathrm{Fe}^{3+}$ ion $(78 \mathrm{pm})^{18}$. The slight shift in XRD peaks change in lattice parameter and crystallite size for different concentrations of Ni-doped $\mathrm{Fe}_{3} \mathrm{O}_{4} \mathrm{NPs}$ indicated that Ni has really doped into the $\mathrm{Fe}_{3} \mathrm{O}_{4}$ structure ${ }^{5}$ and the consecutive peak shift represents that the prepared nanomaterials are not a physical mixtures ${ }^{19}$.

To investigate the effects of $\mathrm{Ni}$ doping on $\mathrm{Fe}_{3} \mathrm{O}_{4} \mathrm{NPs}$ structural characteristics, Average crystalline size is calculated for (311) diffraction peak using Debye-Scherrer formula by equation (1). 


$$
\mathrm{D}=\frac{K \lambda}{\beta \cos \theta}
$$

Where, wavelength $(\lambda)=1.54^{\mid}$A of incident X-rays, the angle of diffraction $(\theta)$, the full width at halfmaximum $(\beta)$ and the grain shape factor $(K)=0.94^{20}$. The lattice constant value can be calculated by equation (2) that is associated with cubic structures:

$$
\mathrm{a}=\mathrm{d}_{\mathrm{hkl}} \sqrt{\mathrm{h}^{2}+k^{2}+l^{2}}
$$

Where Miller indices (h k l) and the inter planar distance $\mathrm{d}_{\mathrm{hkl}}{ }^{21}$.

The broad diffraction peaks for the prepared samples represent the formation of NPs. When the concentration of dopant is above 1 atomic \% (in case of NF3-NF5) broad diffraction peaks observed which means particles size decreased. The variation of the crystallite size of the NPs does not linearly depend on Ni doping concentration can be ascribed to the different dry gel formation time of the spinel ferrite, which favored the formation of new nuclei and preventing further growth of particles ${ }^{22}$ represented in Table-1. The crystallite size decreased from $11.5 \mathrm{~nm}$ to $5.01 \mathrm{~nm}$ with an increase of Ni doping level from $0.5 \%$ to $2 \%$ and increased again when the percentage of $\mathrm{Ni}$ dopant increased to 2.5, it suggests that $\mathrm{Ni}$ at $2 \%$ is the doping limit in $\mathrm{Fe}_{3} \mathrm{O}_{4}$ lattice. All these changes indicate the doping of Ni took place in $\mathrm{Fe}_{3} \mathrm{O}_{4}$ lattice ${ }^{23}$.

The peak intensity decreased when $\mathrm{Fe}_{3} \mathrm{O}_{4}$ doped with different concentrations $(0.5 \%, 1 \%$, $1.5 \%$, and 2.0 $\%)$ of nickel, and the presence of nucleation centers in nickel increase the width of the diffraction peaks demonstrating a decrease of the grain size with respect to the pure sample ${ }^{2}$. Registered broad and lowintensity diffraction peaks confirm the high dispersion of prepared spinels ${ }^{24}$.

The lattice parameter decreased with the increasing amount of $\mathrm{Ni}^{2+}$ ions in magnetite $\left(\mathrm{Fe}_{3} \mathrm{O}_{4}\right) \mathrm{NPs}$, since the ionic radius of $\mathrm{Ni}^{2+}\left(0.69 \mathrm{~A}^{\circ}\right)$ is smaller than the ionic radius of $\mathrm{Fe}^{2+}\left(0.77 \mathrm{~A}^{\circ}\right)$ ions, and also Partial substitution of $\mathrm{Ni}$ ions with $\mathrm{Fe}$ ions in $\mathrm{Fe}_{3} \mathrm{O}_{4} \mathrm{NPs}$, which represents the deviation from Vegarad's law as mentioned in the previous paper ${ }^{5,25}$. The increase in lattice parameters can be due to interstitial incorporation of $\mathrm{Ni}$ ions in $\mathrm{Fe}_{3} \mathrm{O}_{4}$ matrix ${ }^{26}$. Cation distributions in tetrahedral and octahedral sites are explained on the basis of change in the intensities of the (220) and (440) planes as they are sensitive to the distribution of cation among tetrahedral site $\mathrm{A}$ and octahedral site $\mathrm{B}$ of the spinel lattice. The variation in $\mathrm{I}_{220}$ and $\mathrm{I}_{440}$ of $\mathrm{NiFe}_{3} \mathrm{O}_{4}(0 \%, 0.5 \%, 1 \%, 1.5 \%, 2 \%, 2.5 \%)$ NPs shown in table $1^{5}$. The deviation in the values of $\mathrm{I}_{220} / \mathrm{I}_{440}$ may be ascribed to the cations distribution at $\mathrm{A}$ and $\mathrm{B}$ site ${ }^{23}$.

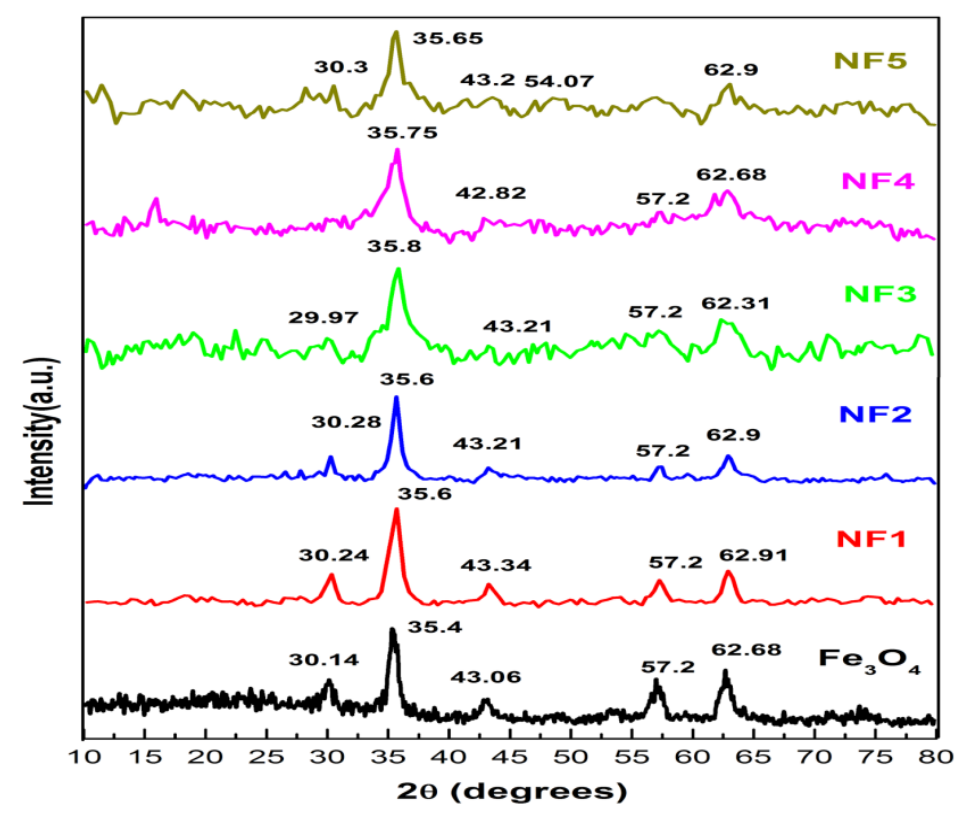

Fig.-1: XRD Patterns of Undoped $\mathrm{Fe}_{3} \mathrm{O}_{4}$ and Different Concentrations of Nickel Doped $\mathrm{Fe}_{3} \mathrm{O}_{4} \mathrm{NPs}$. 


\section{SEM}

The morphology of the $\mathrm{NiFe}_{3} \mathrm{O}_{4} \mathrm{NPs}$ was studied using SEM. Figure-2 shows the SEM graphs of the undoped and $\mathrm{Ni}$-doped $\mathrm{Fe}_{3} \mathrm{O}_{4}$ nanomaterials. SEM images revealed that the undoped $\mathrm{Fe}_{3} \mathrm{O}_{4} \mathrm{NPs}$ undergo agglomeration form due to the magnetic interaction between the particles. The existence of high agglomerated particles indicates pore-free crystallites. The SEM images also show the agglomerated form of $\mathrm{NiFe}_{3} \mathrm{O}_{4}$ due to the high surface energies possessed by $\mathrm{NPs}^{27}$. The $\mathrm{NiFe}_{3} \mathrm{O}_{4} \mathrm{NPs}$ were observed as uniform grains with spherical shaped confirming the crystalline structure of $\mathrm{NiFe}_{3} \mathrm{O}_{4}$ which is also detected by the XRD profile ${ }^{15}$. It should be noted that the X-ray estimated sizes are in all cases slightly vary with those determined by SEM shown in Table-2. The difference between X-ray and SEM data comes from the low signal/background ratio and the noisy pattern of the XRD peaks ${ }^{28}$. The mean size of the particle decreases from $10.12 \mathrm{~nm}$ to $5.80 \mathrm{~nm}$ with the increase of nickel concentration into $\mathrm{Fe}_{3} \mathrm{O}_{4}$ nanoparticles and are also in good agreement with aparticle size values obtained from XRD. It shows that the morphology of Ni-doped sample is significantly changed; hence, the presence of Ni has a key role in the variation of particle sizes ${ }^{29}$.
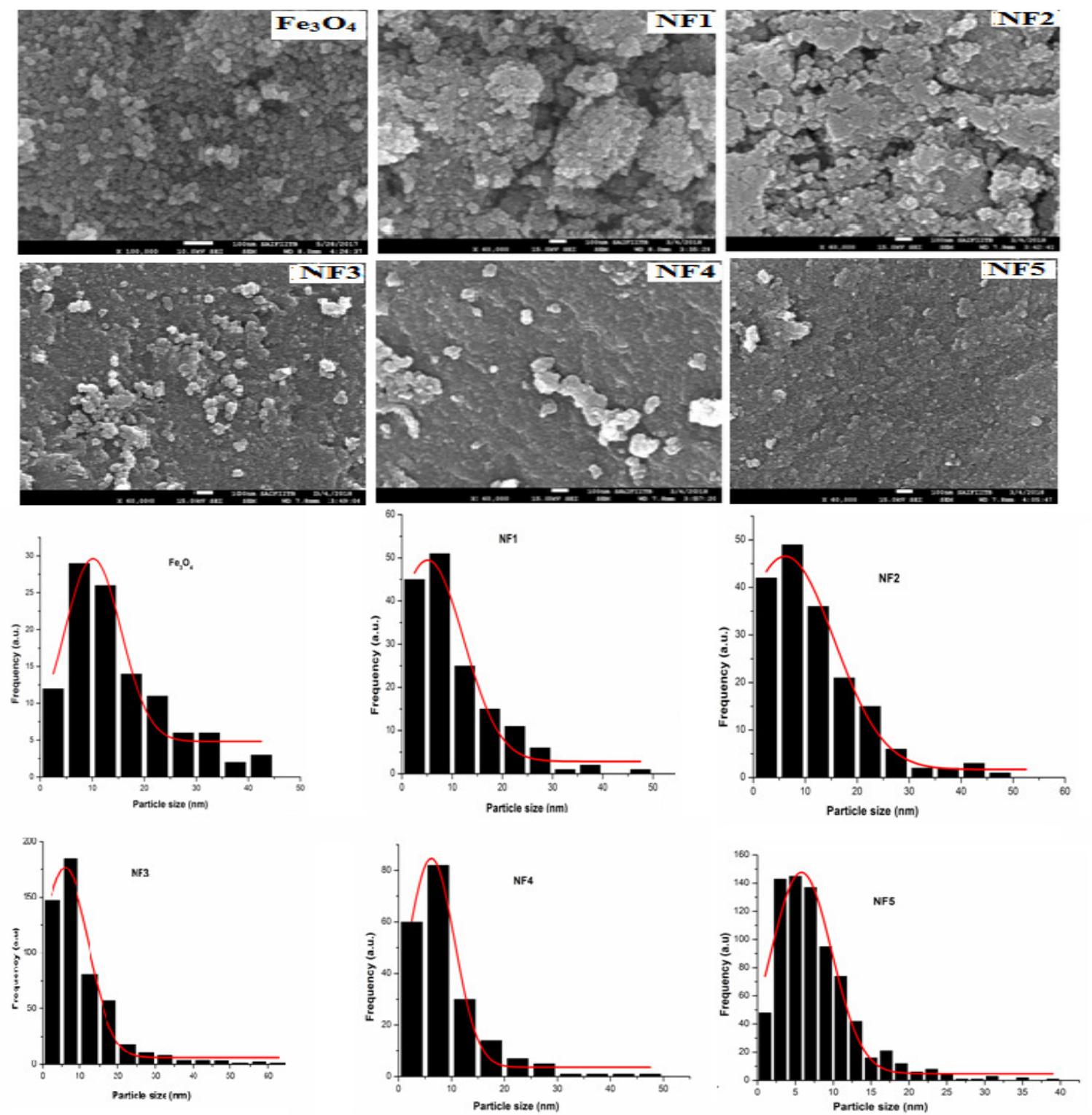

Fig.-2: SEM Images of Undoped $\mathrm{Fe}_{3} \mathrm{O}_{4}$ and Different Concentrations of Nickel Doped $\mathrm{Fe}_{3} \mathrm{O}_{4}$ NPs and their Particle size distribution curves. 
RASĀYAN J. Chem.

Vol. 12 | No. 2 |531 - 536| April - June | 2019

Table-1: Summary of Doping Concentrations, Lattice Parameters and Average Crystalline Size of Ni Doped $\mathrm{Fe}_{3} \mathrm{O}_{4}$ Nanomaterials.

\begin{tabular}{c|c|c|c|c|c}
\hline Sample & $\begin{array}{c}\text { Different } \\
\text { Concentrations of Ni } \\
\text { Doped } \mathrm{Fe}_{3} \mathrm{O}_{4} \mathrm{NPs}\end{array}$ & $\begin{array}{c}\text { Interplanar } \\
\text { Spacing } \\
\text { d Angstroms }\end{array}$ & $\begin{array}{c}\text { Lattice } \\
\text { Constant (a) }\end{array}$ & $\begin{array}{c}\text { Average } \\
\text { Crystalline Size } \\
\text { (nm) }\end{array}$ & $\mathrm{I}_{220} / \mathrm{I}_{440}$ \\
\hline $\mathrm{Fe}_{3} \mathrm{O}_{4}$ & $0 \%$ & 2.522 & 8.36 & 11.5 & 0.845 \\
\hline $\mathrm{NF} 1$ & $0.5 \%$ & 2.514 & 8.33 & 7.65 & 0.916 \\
\hline $\mathrm{NF} 2$ & $1.0 \%$ & 2.516 & 8.34 & 9.09 & 0.958 \\
\hline $\mathrm{NF3}$ & $1.5 \%$ & 2.503 & 8.30 & 5.01 & 0.643 \\
\hline $\mathrm{NF} 4$ & $2.0 \%$ & 2.507 & 8.31 & 5.01 & 0.498 \\
\hline $\mathrm{NF5}$ & $2.5 \%$ & 2.514 & 8.33 & 6.32 & 0.955 \\
\hline
\end{tabular}

Table-2: Average Size of the Nanomaterials Obtained from XRD and SEM Images.

\begin{tabular}{c|c|c|c|c|c|c}
\hline Sample & $\mathrm{Fe}_{3} \mathrm{O}_{4}$ & $\mathrm{NF} 1$ & $\mathrm{NF} 2$ & $\mathrm{NF} 3$ & $\mathrm{NF} 4$ & $\mathrm{NF5}$ \\
\hline Average particle size (nm) from XRD & 11.5 & 7.65 & 9.09 & 5.01 & 5.01 & 6.32 \\
\hline Average particle size (nm) from SEM & 10.12 & 5.10 & 6.14 & 5.95 & 6.19 & 5.80 \\
\hline
\end{tabular}

\section{FTIR}

Chemical structure of the prepared nanomaterials can be determined using FTIR spectroscopy. FT-IR peaks corresponding to the prepared nanomaterials are displayed in Table-3. FTIR spectrum of the Undoped $\mathrm{Fe}_{3} \mathrm{O}_{4} \mathrm{NPs}$ and different concentrations of Ni-doped $\mathrm{Fe}_{3} \mathrm{O}_{4}$ NPs (frequency range of 4000-500 $\mathrm{cm}^{-1}$ ) were shown in Fig.-3. The bands at 552 and $464 \mathrm{~cm}^{-1}$ represented vibration bands of Fe-O bond. The spectrum shows important bands near 3394.1 and $162.9 \mathrm{~cm}^{-1}$ is accredited to the absorbed water or $\mathrm{OH}^{-}$on the surface of the sample. FTIR bands at 563.2 and $433.5 \mathrm{~cm}^{-1}$ indicate the formation of $\mathrm{Fe}_{3} \mathrm{O}_{4}$ $\mathrm{NPs}^{30}$. It is caused by the stretching vibrations of the tetrahedral Fe-O bond. This stretching mode suggests the successful substitution of $\mathrm{Ni}$ ion in $\mathrm{Fe}_{3} \mathrm{O}_{4} \mathrm{NPs}$ which also established by X-ray diffraction and composition analysis. It represents that there is a slight shift in all the characteristic peaks towards higher wave number which can be understood as the difference in the bond length between $\mathrm{Fe}, \mathrm{Ni}$ and $\mathrm{O}$ ions that occurs when $\mathrm{Ni}$ ions replace Fe ions. Thus, FTIR analysis confirming the successful doping of $\mathrm{Ni}$ ion into $\mathrm{Fe}_{3} \mathrm{O}_{4}$ lattice ${ }^{31}$.

Table-3: Representation of Functional Groups of Undoped $\mathrm{Fe}_{3} \mathrm{O}_{4}$ and Ni Doped $\mathrm{Fe}_{3} \mathrm{O}_{4} \mathrm{NPs}$ (Different Concentrations) from FTIR Spectra

\begin{tabular}{l|c|c|c|c|c|c}
\hline \multirow{2}{*}{ Mode of Vibration } & \multicolumn{2}{|c}{ Vibration Frequency for Different Ni Concentrations } & \multicolumn{1}{c}{} \\
\cline { 2 - 8 } & $\mathrm{Fe}_{3} \mathrm{O}_{4} \mathrm{~cm}^{-1}$ & $\mathrm{NF} 1 \mathrm{~cm}^{-1}$ & $\mathrm{NF} 2 \mathrm{~cm}^{-1}$ & $\mathrm{NF} 3 \mathrm{~cm}^{-1}$ & $\mathrm{NF} 4 \mathrm{~cm}^{-1}$ & $\mathrm{NF}^{-1} \mathrm{~cm}^{-1}$ \\
\hline Bending vibrations of -OH group & 3394.1 & 3413.5 & 3309.4 & 3378.8 & 3380.7 & 3388.4 \\
\hline Stretching vibrations of -OH group & 1621.9 & 1623.8 & 1621.9 & 1621.9 & 1621.9 & 1621.9 \\
\hline $\begin{array}{l}\text { The symmetric C=O stretching } \\
\text { vibration of the carboxylate }\left(\mathrm{CO}^{2-}\right) \\
\text { group }\end{array}$ & 1382.7 & 1396.2 & 1394.3 & 1394.3 & 1396.2 & 1392.4 \\
$\begin{array}{l}\text { stretching vibrations of the } \\
\text { tetrahedral } \\
\text { Fe-O bond }\end{array}$ & 563.2 & 566.8 & 568.9 & 588.2 & 592.1 & 610.2 \\
$\begin{array}{l}\text { stretching vibrations of the } \\
\text { octahedral } \\
\text { Fe-O bond }\end{array}$ & 433.5 & 443.5 & 454.3 & 454.2 & 430.5 & 433.5 \\
\hline
\end{tabular}

\section{Optical properties}

Figure-4 shows the DRS-UV-Visible spectroscopy of undoped $\mathrm{Fe}_{3} \mathrm{O}_{4} \mathrm{NPs}$ and different concentrations of $\mathrm{Ni}$-doped $\mathrm{Fe}_{3} \mathrm{O}_{4}$ NPs. The absorption spectrums were measured to investigate Ni doping effect on $\mathrm{Fe}_{3} \mathrm{O}_{4}$ 
NPs optical properties such as optical absorption and band gap. The absorbance spectrum of undoped $\mathrm{Fe}_{3} \mathrm{O}_{4}$ NPs shows the absorbance is in the UV region of the wavelength $321 \mathrm{~nm}$, and the same shifted towards the higher wavelength such as 328 and $325 \mathrm{~nm}$ for concentrations of dopant increases from 1-2.5 atomic \%. While, the absorption edge lies between 393-658 $\mathrm{mm}$. When, Ni doping level has increased the absorbance of the samples increased due to the dopant impurities. Absorption properties of all the samples give similar UV-Visible absorption spectra the only difference is that the absorption moves to longer and longer wavelengths. This infers the amount of delocalization in the NPs increases with increase in Ni content $^{32}$. $\mathrm{Fe}_{3} \mathrm{O}_{4}$ (magnetite) has both direct and indirect band gaps ${ }^{33-37}$.
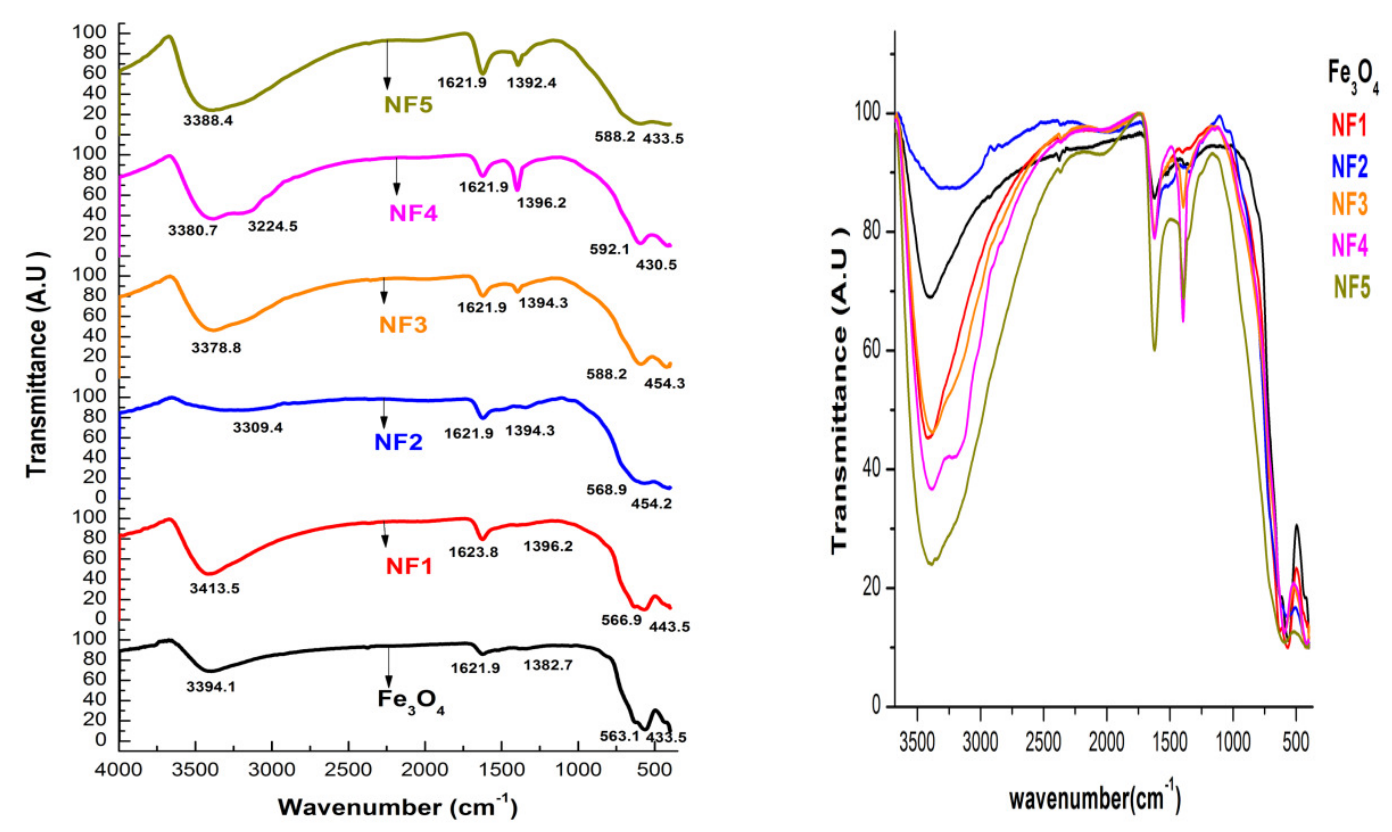

Fig.-3:FTIR Spectra of Undoped $\mathrm{Fe}_{3} \mathrm{O}_{4}$ and Different Concentrations of Nickel Doped $\mathrm{Fe}_{3} \mathrm{O}_{4} \mathrm{NPs}$.

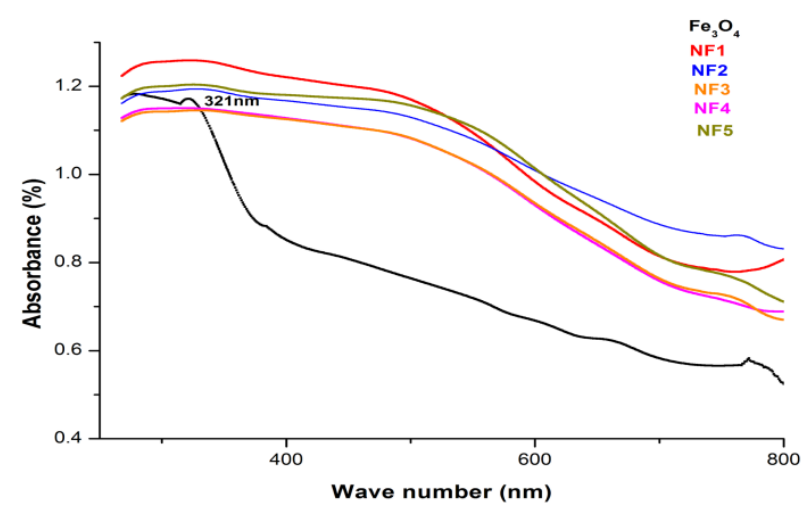

Fig.-4: DRS-UV-Visible spectra of undoped $\mathrm{Fe}_{3} \mathrm{O}_{4} \mathrm{NPs}$ and different concentrations of Ni-doped $\mathrm{Fe}_{3} \mathrm{O}_{4} \mathrm{NPs}$.

The energy gap values of undoped $\mathrm{Fe}_{3} \mathrm{O}_{4}$ and different concentrations of Ni-doped $\mathrm{Fe}_{3} \mathrm{O}_{4} \mathrm{NPs}$ were calculated using Tauc's equation (3) in which the extrapolation from the absorption edge gives the $\mathrm{E}_{\mathrm{g}}$ value.

$$
\alpha h v=A\left(h v-E_{g}\right)^{\mathrm{n} / 2}
$$


Absorption coefficient $(\alpha)$, constant (A), $\mathrm{n}$ is 0.5 (Direct transition), energygap $\left(\mathrm{E}_{\mathrm{g}}\right), \mathrm{h}$ is Planck's constant $\left(\mathrm{h}=6.625 \times 10^{-34} \mathrm{~J} . \mathrm{Sec}\right)$, frequency $(\mathrm{v})$. Following the direct band-gap rule $(\alpha \mathrm{hv})^{2}=\mathrm{A}(\mathrm{h} v-\mathrm{Eg})$, the curve of $(\alpha h v)^{2} \mathrm{Vs}$ hv and the indirect band-gap rule $(\alpha h v)^{1 / 2}=\mathrm{A}\left(\mathrm{hv}-\mathrm{E}_{\mathrm{g}}\right)$, the curve of $(\alpha h v)^{1 / 2} \mathrm{~V}$ shvwas plotted as shown in Fig.-5(a) and (b) ${ }^{38}$. Obtained results were represented in Table-4.
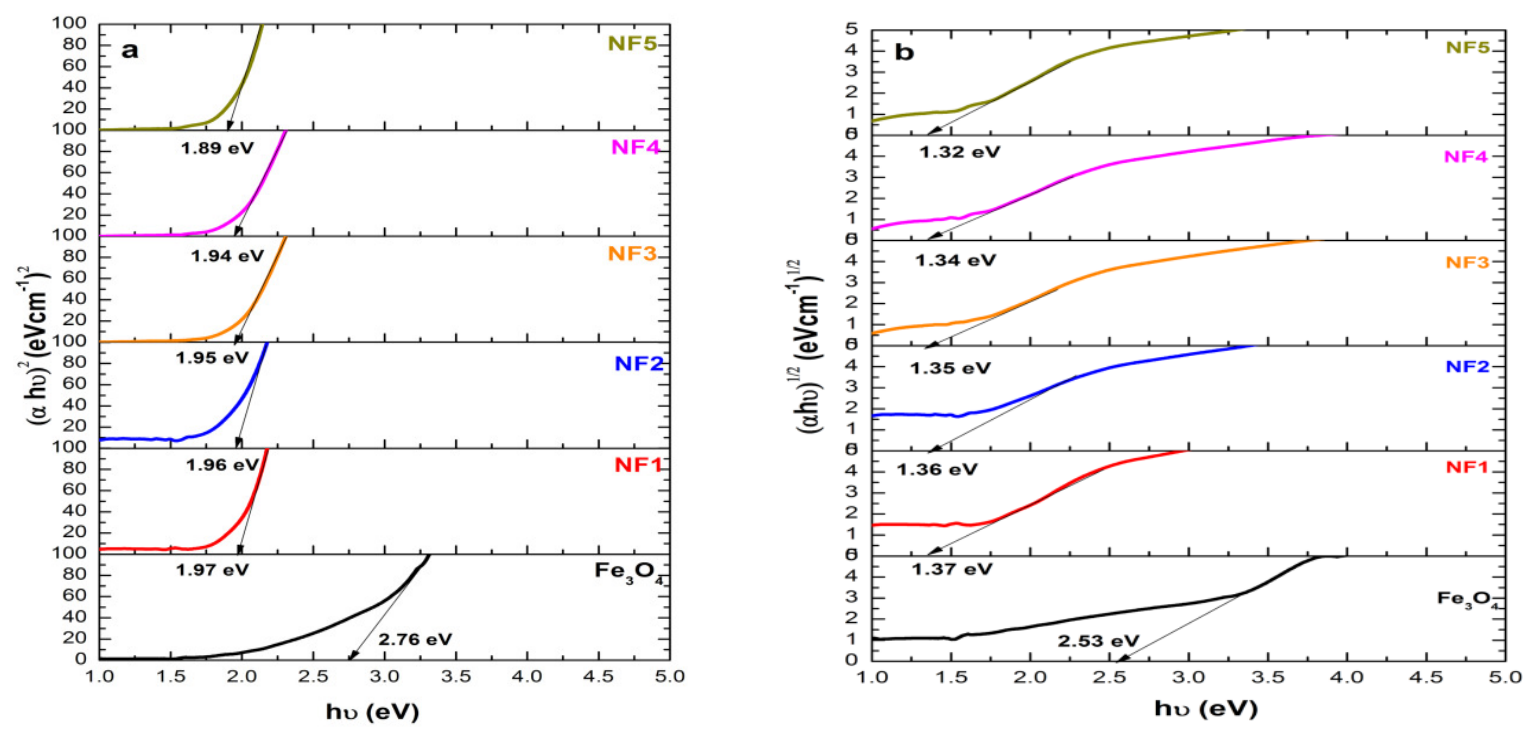

Fig.-5(a) and (b): Tauc Plots of Undoped $\mathrm{Fe}_{3} \mathrm{O}_{4}$ and Different Concentrations of Nickel Doped Fe $\mathrm{O}_{4} \mathrm{NPs}_{\text {for Direct }}$ and Indirect Bad Gap Energies.

Table-4: Direct and Indirect Energy Band Gap Values of Undoped $\mathrm{Fe}_{3} \mathrm{O}_{4}$ and Different Concentrations of Ni Doped $\mathrm{Fe}_{3} \mathrm{O}_{4} \mathrm{NPs}$.

\begin{tabular}{c|c|c|c}
\hline Sample & $\begin{array}{c}\text { Different Concentrations of Ni } \\
\text { Doped } \mathrm{Fe}_{3} \mathrm{O}_{4} \mathrm{NPs}\end{array}$ & $\begin{array}{c}\text { Direct Energy Band Gap } \\
\text { Value }(\mathrm{eV})\end{array}$ & $\begin{array}{c}\text { Indirect Energy Band } \\
\text { Gap Value (eV) }\end{array}$ \\
\hline $\mathrm{Fe}_{3} \mathrm{O}_{4}$ & $0 \%$ & 2.76 & 2.53 \\
\hline $\mathrm{NF} 1$ & $0.5 \%$ & 1.97 & 1.37 \\
\hline $\mathrm{NF} 2$ & $1.0 \%$ & 1.96 & 1.36 \\
\hline $\mathrm{NF} 3$ & $1.5 \%$ & 1.95 & 1.35 \\
\hline $\mathrm{NF} 4$ & $2.0 \%$ & 1.94 & 1.34 \\
\hline $\mathrm{NF5}$ & $2.5 \%$ & 1.89 & 1.32 \\
\hline
\end{tabular}

Ni-doped $\mathrm{Fe}_{3} \mathrm{O}_{4}$ at different concentrations of nickel showed a slight decrease in the band gap compared to pure $\mathrm{Fe}_{3} \mathrm{O}_{4}$ with the increase of nickel concentration. The decrease in the energy gap is not related to the size of a particle may be due to the network distortions narrowing the band gap, the presence of nickel ions in the $\mathrm{Fe}_{3} \mathrm{O}_{4}$ medium and the creation of impurity energy levels with the band gap. It represents that the samples have the potential ability for photocatalytic degradation of organic contaminants in waste water under visible-light irradiation ${ }^{5,20,24}$.

\section{CONCLUSION}

Undoped $\mathrm{Fe}_{3} \mathrm{O}_{4}$ NPs and Ni-doped $\mathrm{Fe}_{3} \mathrm{O}_{4}$ NPs (NF1, NF2, NF3, NF4 and NF5) were synthesized using Chemical co-precipitation technique. XRD peaks represented all the synthesized samples exhibited the cubic inverse spinel structure. No new phases were found even at higher doping concentration $(2.5 \%$ of Ni-doped). The intensity of the diffracted peaks varied with an increase in the concentration of Ni dopant. The FTIR characteristic peaks shift towards higher wave number confirmed the successful doping of Ni ion into $\mathrm{Fe}_{3} \mathrm{O}_{4}$ lattice. Energy gap value decreased from $2.76 \mathrm{eV}$ to $1.89 \mathrm{eV}$ (direct band gap value) and 
RASĀYAN J. Chem.

Vol. 12 | No. 2 |531 - 536| April - June | 2019

$2.53 \mathrm{eV}$ to1.32 eV (indirect band gap value) with the increase of Ni concentration, which are the most essential features for photocatalytic applications.

\section{ACKNOWLEDGMENT}

The authors express sincere gratitude to Prof. L.S.S. Reddy (Vice-Chancellor), Dr. K.L. Narayana (Dean, $\mathrm{R} \& \mathrm{D}$ ), and K L E F for their continuous support and providing laboratory facilities for this current work.

\section{REFERENCES}

1. H. Mansour, R. Bargougui, C. Autret-Lambert, A. Gadri and S. Ammar, J. Phys. Chem. Solids, (2018), DOI: 10.1016/j.jpcs.2017.11.013.

2. A. Lassoued, M. S. Lassoued, S. G. Granda, B. Dkhil, S. Ammar and A. Gadri1, J.Materials Science: Materials in Electroni, (2018), DOI: 10.1007/s10854-018-8543-0.

3. J. C. Bear, P. D. McNaughter, P. Southern, P. O. Brien and C. W. Dunnill, Crystals, 5, 312(2015), DOI:10.3390/cryst5030312.

4. M. Mahdavi, F. Namvar, M. B. Ahmad and R. Mohamad, Molecules, 18, 5954(2013) DOI:10.3390/molecules18055954.

5. S. Anjum, H. Saleem, K. Rasheed, R. Zia, S. Riaz and A. Usman, J. Supercond., (2016), DOI: 10.1007/s10948-016-3832-4.

6. S. H. Chaki, T. J. Malek, M. D. Chaudhary, J. P. Tailor and M. P. Deshpande, Adv. Nat. Sci.: Nanosci. Nanotechnol., 6, 035009 (2015), DOI: 10.1088/2043-6262/6/3/035009/pdf.

7. F. Fajaroh, H. Setyawan, W. Widiyastuti and S. Winardi, Advanced Powder Technology, 23, 328 (2012), DOI: 10.1016/j.apt.2011.04.007.

8. D. L. Paiva, A. L. Andrade, M. C. Pereira, J. D. Fabris, R. Z. Domingues and M. E. Alvarenga, Hyperfine Interact, (2015), DOI: 10.1007/s10751-015-1124-1.

9. T. A. Lastovina, A. P. Budnyk, S. P. Kubrin and A. V. Soldatov, Mendeleev Commun, 28, 167(2018),

10. S. Shaker, S. Zafarian, CH. Shilpa Chakra and K. Venkateswara Rao, Int. J. Innov. Res. Sci. EngTechnol., 2, 7 (2013).

11. G. Salazar-Alvarez, M. Muhammed and A. A. Zagorodni, Chem. Eng. Sci., 61, 4625(2006), DOI: 10.1016/j.ces.2006.02.032.

12. K. Hedayati , M. Goodarzi and D. Ghanbari, J. Nanostruct., 7, 32(2017).

13. R. Rahimi,M. Rabbani and G. Kareh, Conference Paper, (2015), DOI: 10.3390/ecsoc-19-a051.

14. S. H. Chaki, T. J. Malek, M. D. Chaudhary, J. P. Tailor and M. P. Deshpande, Adv. Nat. Sci.: Nanosci. Nanotechnol., 6, 035009 (2015), DOI: 10.1088/2043-6262/6/3/035009.

15. K. Mohanraj and G. Sivakumar, Sains Malaysiana, 46, 1935(2017), DOI: 10.17576/jsm-2017-461032.

16. M. Aghazadeh, I. Karimzadeh, M. R. Ganjali and A. Behzad, J.Mater Sci: Mater Electron., 23, (2017), DOI:10.1007/s10854-017-7757-x.

17. M. Aghazadeh, M. GhannadiMaragheh and P. Norouzi, Int. J. Electrochem. Sci., 13, 1355 (2018), DOI: $10.20964 / 2018.02 .40$.

18. C. Thangamaniet al., Surface Review and Letters, (2018), DOI: 10.1142/S0218625X18501846.

19. H. Chen, L. Ding, W. Sun, Q. Jiang, J.Hu and J. Li, The Royal Society of Chemistry, (2013), DOI: 10.1039/C5RA10268E.

20. Z. Aghajani, A. AsgharEngashteVahed and M. RezaZand Monfared, J.Mater.Sci: Mater Electron, DOI: $10.1007 / \mathrm{s} 10854-017-7666-\mathrm{z}$.

21. Z. R. Marand, M. H. R. Farimani and N. Shahtahmasebi, Nanomed. J., 1, 238 (2014).

22. M. Satalkar and S. N. Kane, IOP Publishing Journal of Physics: Conference Series, 755 (2016), DOI: $10.1088 / 1742-6596 / 755 / 1 / 012050$.

23. Chapter-6, Preparation and characterization of $\mathrm{Ni}$ doped $\mathrm{SnO}_{2}$ Compounds, DOI: 10603/117665/15/15_chapter\%206.pdf.

24. Z. Cherkezova-Zheleva, K. Zaharieva, K. Buchkov, B. Blagoevc and I. Mitov, ActaPhysicaPolonica A, 126, (2014), DOI: 10.12693/APhysPolA.126.912. 
RASĀYAN J. Chem.

Vol. 12 | No. 2 |531 - 536| April - June | 2019

25. F. Leonard Deepak et.al, J. Phys. Chem. C, (2015), DOI: 10.1021/acs.jpcc.5b01575

26. S.Jurvetson, Chapter III, DOI: 10603/175811/11/11_chapter3.pdf

27. S. Sagadevana, Z. Z. Chowdhuryb and R. F. Rafiquec, Materials Research, 21, (2018), DOI: 10.1590/1980-5373-MR-2016-0533

28. S. Larumbe et.al, J. Nanoscience and Nanotechnology, 12, 1 (2012), DOI:10.1166/jnn.2012.5769.

29. R. Suresh, K. Giribabu, R. Manigandan, L. Vijayalakshmi, A. Stephen and V. Narayanan, AIP Conference Proceedings, 1576, 122 (2014), DOI:10.1063/1.4861998.

30. C. Thangamani, M. Ponnar, P. Priyadharshini, P. Monisha, S. S. Gomathi and K. Pushpanathan, Surface Review and Letters, (2018), DOI: 10.1142/S0218625X18501846.

31. M. U. Anuprathap, B. Kaur and R. Srivastava, J.ColloidInterf. Sci., 370, 144(2012), DOI:10.1016/j.jcis.2011.12.074

32. N. M. Basith, J. J. Vijaya, L. J. Kennedy and M. Bououdina, Mater.Sci.Semicond.Pro, 17, 110(2014), DOI: $10.1016 / j . j m s t .2014 .07 .013$.

33. H. Viltres, O. F. Odio, R. Borja, Y. Aguilera and E. Reguera, IOP Conf. Series: Journal of Physics: Conf. Series, 792 (2017), DOI: 10.1088/1742-6596/792/1/012078.

34. P. Mallick, and B. N. Dash, Nanoscience and Nanotechnology, 3, 130(2013), DOI: 10.5923/j.nn.20130305.04

35. D. Anjali Jain and R. V. Nandedkar, Materials Today: Proceedings, 3, 2069(2016), DOI: 10.1016/j.matpr.2016.04.110.

36. H. El. Ghandoor, H. M. Zidan, M. M. H. Khalil and M. I. M. Ismail, Int. J. Electrochem. Sci., 7, 5734(2012).

37. K. Mohanraj and G. Sivakumar, SainsMalaysiana, 46, 1935(2017), DOI: 10.17576/jsm-2017-461032.

38. M. M. Rahman, M. MusarrafHussain, and A. M. Asiri, PLOS ONE,(2017), DOI: 10.1371/journal.pone.0177817.

[RJC-5054/2018] 